\title{
SISTEM PEMILIHAN LAPTOP TERBAIK DENGAN MENGGUNAKAN METODE WEIGHTED PRODUCT (WP)
}

\author{
Susliansyah'; ${ }^{1}$ Ririn Restu Aria² ${ }^{2}$ Susi Susilowati ${ }^{3}$ \\ Program Sistem Informasi 1,2,3 \\ Universitas Bina Sarana Informatika \\ http://www.bsi.ac.id \\ ${ }^{1}$ susliansyah.slx@bsi.ac.id, ${ }^{2}$ ririn.rra@bsi.ac.id, ${ }^{3}$ susi.sss@bsi.ac.id
}

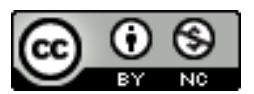

Ciptaan disebarluaskan di bawah Lisensi Creative Commons Atribusi-NonKomersial 4.0 Internasional.

\begin{abstract}
The Weighted Product method requires a normalization process because this method assumes the results of evaluating each attribute. The results of these multiplications have not been meaningful if they have not been compared (divided) with standard values. The weight for the benefit attribute functions as a positive power in the multiplication process, while the weight of the cost functions as a negative rank. The Weighted Product method uses multiplication as a linking attribute rating, where the rating of each attribute must be raised first with the corresponding weight. Weighting Product Weighted method is calculated based on the level of importance. This system requires input weight values based on prospective buyers' needs in the form of prices, RAM capacity, processor type, Harddisk capacity, and VGA (Video Grapphics Array). The results of this study provide laptop recommendations according to specification requirements for prospective buyers with 100\% calculation accuracy based on manual calculations and calculations on laptop selection decision support systems.
\end{abstract}

Keywords: Selection, Laptop, best, Weighted Products

Intisari-Metode Weighted Product memerlukan proses normalisasi karena metode ini mengaluhkan hasil penilaian setiap atribut. Hasil perkalian tersebut belum bermakna jika belum dibandingkan (dibagi) dengan nilai standart. Bobot untuk atribut manfaat berfungsi sebagai pangkat positif dalam proses perkalian, sementara bobot biaya berfungsi sebagai pangkat negatif. Metode Weighted Product menggunakan perkalian sebagai untuk menghubungkan rating atribut, dimana rating setiap atribut harus dipangkatkan dulu dengan bobot yang
bersangkutan.Pembobotan metode Weighted Product dihitung berdasarkan tingkat kepentingan. Sistem ini membutuhkan masukan nilai bobot berdasarkan kebutuhan calon pembeli berupa harga, kapasistas RAM, jenis prosesor, kapasitas Harddisk, dan VGA (Video Grapphics Array).Hasil dari pennelitian ini memberikan saran laptop sesuai dengan kebutuhan spesifikasi untuk calon pembeli dengan tingkat akurasi perhitungan $100 \%$ berdasarkan perhitungan manual dan perhitungan pada sistem pendukung keputusan pemilihan laptop.

Kata Kunci: Pemilihan, Laptop, terbaik Weighted Produk

\section{PENDAHULUAN}

Sistem Pendukung Keputusan (SPK) merupakan suatu penerapan sistem informasi yang ditujukan untuk membantu pimpinan dalam proses pengambilan keputusan (Hatta, Rizaldi, \& Khairina, 2016). Sistem Pendukung Keputusan (SPK) digunakan untuk membantu pengambilan keputusan berdasarkan kriteria yang sudah ditentukan (Yoni \& Mustafidah, 2016). Pengambilan keputusan dilakukan dengan pendekatan sistematis terhadap permasalahan melalui proses pengumpulan data menjadi informasi serta ditambah dengan faktorfaktor yang perlu dipertimbangkan dalam pengambilan keputusan (Kurniasih, 2013).

Salah satu metode dalam FMADM yang cukup terkenal adalah metode weighted product (WP). Metode WP cukup banyak digunakan untuk pengambilan keputusan karena metodenya yang sederhana dengan memasukkan semua faktor dan komputasinya cepat (Supriyono \& Sari, 2015), 
serta mampu memilih alternatif terbaik dari sejumlah alternatif (Zai, Mesran, \& Buulolo, 2017). Pada metode Weighted Product (WP) menggunakan perkalian untuk menghubungkan rating atribut, dimana rating setiap atribut harus dipangkatkan dulu dengan bobot atribut yang bersangkutan (Nurjannah, Arifin, \& Khairina, 2015).

Banyak merek dan tipe laptop yang dijual di pasaran, tentunya dengan harga yang bervariasi pula, membuat pengguna menjadi kesulitan dalam menentukan pilihan yang sesuai dengan kebutuhannya (Sanyoto, Handayani, \& Widanengsih, 2017). Tidak jarang juga pengguna membeli laptop dengan spesifikasi yang tidak disesuaikan dengan kegunaannya (Syafitri, Sutardi, \& Dewi, 2016). Misalnya saja, membeli laptop dengan spesifikasi tinggi, tetapi penggunaannya hanya

sebatas untuk pekerjaan mengetik. Padahal sebenarnya dengan spesifikasi "tinggi" tersebut, pengguna dapat menggunakan laptop untuk pekerjaan lain yang lebih berat, desain grafis misalnya, Hidayatullah dalam (Hartanto \& Prasetiyowati, 2012).

\section{BAHAN DAN METODE}

Metode WP dapat membantu dalam mengambil keputusan pemilihan laptop, akan tetapi perhitungan dengan menggunakan metode WP ini hanya menghasilkan nilai terbesar yang akan terpilih sebagai alternatif yang terbaik. Perhitungan akan sesuai dengan metode ini apabila alternatif yang terpilih memenuhi kriteria yang telah ditentukan. Metode WP ini lebih efisien karena waktu yang dibutuhkan dalam perhitungan lebih singkat. Bobot untuk atribut manfaat berfungsi sebagai pangkat positif dalam proses perkalian, sementara bobot biaya berfungsi sebagai pangkat negatif (Syafitri et al., 2016).

Perbaikan bobot untuk $\Sigma=1$ menggunakan Persamaan (1).

$W_{j}=\frac{W_{j}}{\sum W_{j}}$

Variabel W adalah pangkat bernilai positif untuk atribut keuntungan dan bernilai negatif untuk atribut biaya. Preferensi untuk alternatif diberikan oleh Persamaan (2).

$S_{i}=\Pi_{j}^{n}=1 X_{i j} W_{j}$

Keterangan:

$\Pi$ : Product

Si : Skor / nilai dari setiap alternatif

Xij : Nilai alternatif ke- i terhadap atribut ke- j wj : Bobot dari setiap atribut atau kriteria $n$ : Banyaknya kriteria

Untuk mencari alternatif terbaik dilakukan dengan Persamaan (3).

$V_{i}=\frac{\Pi_{j}^{n}=1 X_{i j} w_{j}}{\Pi_{j}^{n}=1\left(X_{j^{*}}\right) w_{j}}$

Dalam penyelesaian pemilihan laptop terbaik dengan menggunakan metode Weighted Product diperlukan kriteria-kriteria dan bobot untuk melakukan perhitungan sehingga akan didapat alternatif terbaik. Berikut merupakan kriteria yang dibutuhkan untuk pengambilan keputusan, berdasarkan parameter dalam menentukan laptop terbaik pada SMK Mandiri Bekasi sebagai berikut:

Tabel 1. Kriteria

\begin{tabular}{cc}
\hline Kriteria & keterangan \\
\hline C1 & Prosesor \\
\hline C2 & RAM \\
\hline C3 & Hrddisk \\
\hline C4 & VGA \\
\hline C5 & Harga \\
\hline
\end{tabular}

Sumber: (SMKMandiriBekasi, 2018)

Dalam kriteria tersebut, maka ditentukan suatu tingkatan kepentingan kriteria berdasarkan nilai bobot yang telah ditentukan. Rating setiap alternatif pada setiap kriteria sebagai berikut:

Tabel 2. Rating Alternatif

\begin{tabular}{l}
$\begin{array}{l}1=\text { Sangat Rendah } \\
2=\text { Rendah }\end{array}$ \\
\hline $3=$ Cukup \\
\hline $4=$ Tinggi \\
\hline $5=$ Sangat Tinggi
\end{tabular}

Sumber: (SMKMandiriBekasi, 2018)

Berdasarkan kriteria dari rating setiap alternatif $\left(\mathrm{A}_{\mathrm{i}}\right)$ pada setiap kriteria $\left(\mathrm{C}_{\mathrm{j}}\right)$ yang telahditentukan, selanjutnya bobot setiap kriteria $(\mathrm{Cj})$.

a. Nilai Bobot Prosesor (C1)

Tabel 3 Kriteria Prosesor

\begin{tabular}{lll}
\hline \multirow{3}{*}{ Prosesor } & Sangat Tinggi & 5 \\
\cline { 2 - 3 } & Tinggi & 4 \\
\cline { 2 - 3 } & Sedang & 3 \\
\cline { 2 - 3 } & Rendah & 2 \\
\hline Sumber: (SMKMandiriBekasi, 2018)
\end{tabular}

Sumber: (SMKMandiriBekasi, 2018) 
Nilai bobot (W) dari masing-masing kriteria prosesor yang telah ditentukan oleh pihak sekolah SMK Mandiri Bekasi.

b. Kriteria Bobot RAM (C2)

Tabel 4 Kreteria Kapasitas RAM

\begin{tabular}{lll}
\hline \multirow{2}{*}{ Kapasitas RAM } & $16 \mathrm{~GB}$ & 5 \\
\cline { 2 - 3 } $8 \mathrm{~GB}$ & 4 \\
\cline { 2 - 3 } $4 \mathrm{~GB}$ & 3 \\
\cline { 2 - 3 } $2 \mathrm{~GB}$ & 2 \\
\hline $1 \mathrm{~GB}$ & 1 \\
\hline
\end{tabular}

Sumber: (SMKMandiriBekasi, 2018)

Nilai bobot (W) dari masing-masing kriteria kapasitas RAM yang telah ditentukan oleh pihak sekolah SMK Mandiri Bekasi.

c. Kriteria Bobot Harddisk (C3)

Tabel 5 Kriteria Harddisk

\begin{tabular}{|c|c|c|}
\hline \multirow{5}{*}{ Kapasitas Harddisk } & $>750 \mathrm{~GB}$ & 5 \\
\hline & 750 GB & 4 \\
\hline & $500 \mathrm{~GB}$ & 3 \\
\hline & 320 GB & 2 \\
\hline & $250 \mathrm{~GB}$ & 1 \\
\hline
\end{tabular}

Sumber: (SMKMandiriBekasi, 2018)

Nilai bobot (W) dari masing-masing kriteria harddisk yang telah ditentukan oleh pihak sekolah SMK Mandiri Bekasi.

d. Kriteria Bobot VGA (C4)

Tabel 6 Kriteria VGA

\begin{tabular}{ccc}
\hline \multirow{3}{*}{ Prosesor } & Sangat Tinggi & 5 \\
\cline { 2 - 3 } & Tinggi & 4 \\
\cline { 2 - 3 } & Sedang & 3 \\
\cline { 2 - 3 } & Rendah & 2 \\
\cline { 2 - 3 } & Sangat Rendah & 1 \\
\hline
\end{tabular}

Sumber: (SMKMandiriBekasi, 2018)

Nilai bobot (W) dari masing-masing kriteria VGA yang telah ditentukan oleh pihak sekolah SMK Mandiri Bekasi.

e. Kriteria Bobot Harga (C5)

Tabel 5 Kriteria Harga

\begin{tabular}{lll}
\hline \multirow{3}{*}{ Harga } & $>15 \mathrm{Jt}$ & 5 \\
\cline { 2 - 3 } & $8-15 \mathrm{Jt}$ & 4 \\
\cline { 2 - 3 } & $6-8 \mathrm{Jt}$ & 3 \\
\hline
\end{tabular}

\begin{tabular}{ll}
\hline $4-6 \mathrm{Jt}$ & 2 \\
\hline $3-4 \mathrm{Jt}$ & 1 \\
\hline
\end{tabular}

Sumber: (SMKMandiriBekasi, 2018)

Nilai bobot (W) dari masing-masing kriteria harga yang telah ditentukan oleh pihak sekolah SMK Mandiri Bekasi.

\section{HASIL DAN PEMBAHASAN}

1. Seleksi Data Alternatif

Beberapa alternatif yang akan diseleksi dengan metode Weighted Product yang dapat dilihat dibawah ini :

Tabel 7 Data Alternatif

\begin{tabular}{|c|c|c|c|c|c|c|}
\hline \multirow[b]{2}{*}{ No } & \multirow[b]{2}{*}{$\begin{array}{c}\text { Altern } \\
\text { atif }\end{array}$} & \multicolumn{5}{|c|}{ Kriteria } \\
\hline & & $\mathrm{C} 1$ & $\mathrm{C} 2$ & $\mathrm{C} 3$ & $\mathrm{C} 4$ & $\mathrm{C} 5$ \\
\hline \multirow[t]{4}{*}{1} & Axioo & Intel & 2 & 500 & Intel HD & 4.1 \\
\hline & - Neon & Celeron & GB & GB & Family & 00 \\
\hline & TNW & N2940 & & & & 00 \\
\hline & $\mathrm{C} 825$ & & & & & 0 \\
\hline \multirow[t]{5}{*}{2} & Axioo & Intel & 2 & 500 & Intel HD & 4.0 \\
\hline & Neon & Celero & GB & GB & Family & 00 \\
\hline & TNNC & $\mathrm{n}$ & & & & 00 \\
\hline & 825 & Quad Core & & & & 0 \\
\hline & & N2920 & & & & \\
\hline \multirow[t]{4}{*}{3} & Acer & AMD A10- & 4 & $1 \mathrm{~TB}$ & AMD & 6.6 \\
\hline & Aspire & 7300 & GB & & Raden & 99 \\
\hline & E5 - & & & & R7 & 00 \\
\hline & 551 & & & & M265 & 0 \\
\hline \multirow[t]{5}{*}{4} & Lenov & Intel Core & 2 & 500 & NVIDIA & 5.3 \\
\hline & o & i3-5005U & GB & GB & GeForce & 99 \\
\hline & Ideap & & & & $920 \mathrm{~A}$ & 00 \\
\hline & & & & & DDR3L & 0 \\
\hline & 100 & & & & $2 \mathrm{~GB}$ & \\
\hline \multirow[t]{4}{*}{5} & Toshi & Intel Core & 2 & 500 & NVIDIA & 6.2 \\
\hline & ba & i3-3227u & GB & GB & GoForce & 00 \\
\hline & $\mathrm{S} 40 \mathrm{~A}$ & & & & GT 740 & 00 \\
\hline & & & & & $\mathrm{M}$ & 0 \\
\hline \multirow[t]{4}{*}{6} & HP & AMD A4 - & 2 & 500 & AMD & 3.8 \\
\hline & $14-$ & 500 & GB & GB & Radeon & 30 \\
\hline & G1024 & & & & HD 833 & 00 \\
\hline & $\mathrm{U}$ & & & & & 0 \\
\hline
\end{tabular}

yang akan diseleksi untuk dijadikan sebagai data dalam mencari laptop terbaik.

2. Menentukan Nilai Bobot Alternatif

Tabel 8. Nilai Bobot Alternatif

\begin{tabular}{llllll}
\hline & \multicolumn{5}{c}{ Kriteria } \\
\cline { 2 - 6 } $\begin{array}{c}\text { Alternati } \\
\text { f }\end{array}$ & $\mathrm{C} 1$ & $\mathrm{C} 2$ & $\mathrm{C} 3$ & $\mathrm{C} 4$ & $\mathrm{C} 5$ \\
\hline A1 & 2 & 1 & 3 & 2 & 5 \\
\hline A2 & 4 & 4 & 3 & 2 & 2 \\
\hline A3 & 1 & 3 & 4 & 5 & 4 \\
\hline A4 & 4 & 1 & 3 & 2 & 5 \\
\hline A5 & 4 & 1 & 3 & 2 & 4 \\
\hline A6 & 4 & 1 & 3 & 2 & 1 \\
\hline
\end{tabular}

Sumber: (SMKMandiriBekasi, 2018) 
Merupakan nilai dari masing-masing kriteria dari setiap data alternatif.

3. Menentukan Nilai Bobot Kriteria

Tabel 9. Nilai Bobot kriteria

\begin{tabular}{ccc}
\hline W1 & Prosesor & 5 \\
\hline W2 & RAM & 4 \\
\hline W3 & Harddisk & 3 \\
\hline W4 & VGA & 5 \\
\hline W5 & Harga & 3 \\
\hline
\end{tabular}

Sumber: (SMKMandiriBekasi, 2018)

Merupakan hasil penentuan Nilai bobot setiap kriteria yang telah didapatkan dari pihak sekolah.

4. Perbaikan Bobot Perkriteria

Setelah mendapatkan nilai bobot pada masing-masing kriteria maka dilakukan perbaikan bobot dari nilai bobot awal.

$W_{j}=\frac{W_{j}}{\sum W_{j}}$

$W_{1}=\frac{5}{5+4+3+5+3}=\frac{5}{20}=0,25$

$W_{2}=\frac{4}{5+4+3+5+3}=\frac{4}{20}=0,2$

$W_{3}=\frac{3}{5+4+3+5+3}=\frac{3}{20}=0,15$

$W_{4}=\frac{5}{5+4+3+5+3}=\frac{5}{20}=0,25$

$W_{5}=\frac{3}{5+4+3+5+3}=\frac{3}{20}=0,15$

Tabel 10. Hasil Perbaikan Bobot Kriteria

\begin{tabular}{cc}
\hline Kriteria & Nilai Bobot \\
\hline W1 & 0,25 \\
\hline W2 & 0,2 \\
\hline W3 & 0,15 \\
\hline W4 & 0,25 \\
\hline W5 & 0,15
\end{tabular}

Sumber: (Susliansyah, Aria, \& Susilowati, 2018)

Merupakan hasil dari perbaikan bobot pada setiap kriteria dari W1 sampai dengan W5.

\section{Perhitungan Nilai Vektor (S)}

Setelah dilakukan perbaikan bobot, dilakukan perhitungan nilai vektor (S), dengan memangkatkan dan mengalikan nilai masing- masing kriteria tersebut dengan bobot yang sudah diperbaiki sebelumnya.

$$
S_{i}=\Pi_{j}^{n}=1 X_{i j} W_{j}
$$

$$
\begin{aligned}
\mathrm{S} 1 & =\left(2^{0,25}\right)\left(1^{0,20}\right)\left(3^{0,15}\right)\left(2^{0,25}\right)\left(5^{0,15}\right) \\
& =1,30990 \\
\mathrm{~S} 2 & =\left(4^{0,25}\right)\left(4^{0,2}\right)\left(3^{0,15}\right)\left(2^{0,25}\right)\left(5^{0,15}\right) \\
& =2,35830
\end{aligned}
$$

$$
\begin{aligned}
\text { S3 } & =\left(1^{0,25}\right)\left(3^{0,2}\right)\left(4^{0,15}\right)\left(5^{0,25}\right)\left(4^{0,15}\right) \\
& =1,86280
\end{aligned}
$$

$$
\begin{aligned}
\mathrm{S} 4 & =\left(4^{0,25}\right)\left(1^{0,2}\right)\left(3^{0,15}\right)\left(2^{0,25}\right)\left(3^{0,15}\right) \\
& =1,55774
\end{aligned}
$$

$$
\begin{aligned}
\mathrm{S} 5 & =\left(4^{0,25}\right)\left(1^{0,2}\right)\left(3^{0,15}\right)\left(2^{0,25}\right)\left(4^{-0,15}\right) \\
& =1,61076
\end{aligned}
$$

$$
\begin{aligned}
\mathrm{S} 6 & =\left(4^{0,25}\right)\left(1^{0,2}\right)\left(3^{0,15}\right)\left(2^{0,25}\right)\left(1^{-0,15}\right) \\
& =1,98308
\end{aligned}
$$

Tabel 11. Hasil Nilai Vektor S

\begin{tabular}{cc}
\hline Alternatif & Nilai Vektor S \\
\hline A1 & 1,309899 \\
\hline A2 & 2,358295 \\
\hline A3 & 1,862802 \\
\hline A4 & 1,557741 \\
\hline A5 & 1,610763 \\
\hline A6 & 1,983082 \\
\hline Total & 10,68258 \\
\hline
\end{tabular}

Sumber: (Susliansyah et al., 2018)

Merupakan hasil dari nilai vektor $\mathrm{S}$ terhadap data alternatif A1 sampai dengan A6.

6. Perhitungan Nilai Vektor (V)

Setelah mendapatkan nilai Vektor (S) langkah selanjutnya yaitu menentukan nilai vektor (V) yaitu, membagi preferensi setiap alternatif dengan jumlah total vektor $\mathrm{S}$

$$
\begin{aligned}
& V_{i}=\frac{\Pi_{j}^{n}=1 X_{i j} w_{j}}{\Pi_{j}^{n}=1\left(X_{j^{*}}\right) w_{j}} \ldots \ldots \ldots \ldots \ldots \ldots . \ldots . \ldots . \ldots . \ldots \\
& V_{1}=\frac{1,309899}{10,68258}=0,122620 \\
& V_{2}=\frac{2,358295}{10,68258}=0,220761 \\
& V_{3}=\frac{1,862802}{10,68258}=0,174378
\end{aligned}
$$




$$
\begin{aligned}
& V_{4}=\frac{1,557741}{10,68258}=0,145821 \\
& V_{5}=\frac{1,610763}{10,68258}=0,150784 \\
& V_{6}=\frac{1,983082}{10,68258}=0,185637
\end{aligned}
$$

Tabel 12. Hasil Nilai Vektor $\mathrm{V}$

\begin{tabular}{cc}
\hline Alternatif & Nilai Vektor V \\
\hline A1 & 0,122620 \\
\hline A2 & 0,220761 \\
\hline A3 & 0,174378 \\
\hline A4 & 0,145821 \\
\hline A5 & 0,150784 \\
\hline A6 & 0,185637 \\
\hline
\end{tabular}

Sumber: (Susliansyah et al., 2018)

Dari hasil perhitungan Vektor $\mathrm{V}$ dari data alternatif A1 sampai A2, dibuatlah perangkingan yaitu:

Tabel 13. Hasil Perangkingan

\begin{tabular}{ccc}
\hline Alternatif & Nilai Vektor V & Perangkinan \\
\hline A1 & 0,122620 & 6 \\
\hline A2 & 0,220761 & 1 \\
\hline A3 & 0,174378 & 3 \\
\hline A4 & 0,145821 & 5 \\
\hline A5 & 0,150784 & 4 \\
\hline A6 & 0,185637 & 2 \\
\hline
\end{tabular}

Sumber: (Susliansyah et al., 2018)

Merupakan hasil perangkingan dari perhitungan nilai vektor $\mathrm{V}$, sehingga diperoleh perurutan perangkingan data altenatif dari peringkat ke 1 sampai peringkat ke 6 adalah: A2, A6, A3, A5, A4 dan A1.

\section{KESIMPULAN}

Penerapan metode Weighted Product dapat digunakan untuk membantu merekomendasikan dalam pemilihan laptop terbaik Di Sekolah SMK Mandiri Bekasi dengan pengurutan nilai alternatif dari nilai alternatif terkecil sampai nilai alternatif terbesar. Dengan menggunakan 5 kriteria yaitu : Prosesor, RAM, Harddisk, VGA, Harga. Alternatif yang diuji dapat diperoleh nilai alternatif yaitu : (1) Axioo - Neon TNW C825 V1 $=0,122620$ (2) Axioo Neon TNNC825 V2=0,220761 (3) Acer Aspire E5 - 551
$V_{3}=0,174378$ (4) Lenovo Ideapad 100 V4= 0,145821 (5) Toshiba S40 A V5=0,150784 (6) HP $14-\mathrm{G} 1024 \mathrm{U}$ V6 $=0,185637$.

\section{REFERENSI}

Hartanto, T., \& Prasetiyowati, M. I. (2012). Sistem Pendukung Keputusan Pemilihan Laptop Berbasis Web dengan Metode Analytical Hierarchy Process ( Studi Kasus: SAMCO COMPUTER ). ULTIMATICS, IV(2), 7-15.

Hatta, H. R., Rizaldi, M., \& Khairina, D. M. (2016). Penerapan Pen erapan Metode Weighted Product U ntuk Pemilihan Lokasi L ahan Baru Pemakaman Muslim Dengan Visualisasi Google Maps. TEKNOSI, 02(03), 85-94.

Kurniasih, D. L. (2013). Sistem Pendukung Keputusan Pemilihan Laptop dengan Metode TOPSIS. Pelita Informatika Budi Darma, III(April), 6-13.

Nurjannah, N., Arifin, Z., \& Khairina, D. M. (2015). Sistem Pendukung Keputusan Pembelian Sepeda Motor Dengan Metode Weighted Product. Jurnal Informatika Mulawarman, 10(2), 2-6.

Sanyoto, G. P., Handayani, R. I., \& Widanengsih, E. (2017). SISTEM PENDUKUNG KEPUTUSAN PEMILIHAN LAPTOP UNTUK KEBUTUHAN OPERASIONAL DENGAN METODE AHP (STUDI KASUS : DIREKTORAT PEMBINAAN KURSUS DAN PELATIHAN KEMDIKBUD). Jurnal Pilar Nusa Mandiri, 13(2), 167-174.

SMKMandiriBekasi. (2018). Sistem Pemilihan Laptop Terbaik Dengan Menggunakan Metode Weighted Product (WP).

Supriyono, H., \& Sari, C. P. (2015). Rumah Tinggal Menggunakan Metode Weighted Product. Jurnal Ilmu Komputer Dan Informatika Pemilihan, 1(1), 23-28.

Susliansyah, Aria, R. R., \& Susilowati, S. (2018). SISTEM PEMILIHAN LAPTOP TERBAIK DENGAN MENGGUNAKAN METODE WEIGHTED PRODUCT (WP).

Syafitri, N. A., Sutardi, \& Dewi, A. P. (2016). Penerapan metode Weighted Product Dalam Sistem Pendukung Keputusan Pemilihan Laptop Berbasis Web. SemanTIK, 2(1), 169176.

Yoni, D. C., \& Mustafidah, H. (2016). Penerapan Metode WP ( Weighted Product ) Untuk Pemilihan Mahasiswa Lulusan Terbaik di 
Fakultas Teknik Universitas Muhammadiyah Purwokerto. JUITA, IV(1), 22-27.

Zai, Y., Mesran, \& Buulolo, E. (2017). Sistem Pendukung Keputusan untuk menentukan Buah Rambutan dengan Kualitas Terbaik menggunakan Metode Weighted Product (WP). Media Informatika Budidarma, 1(1), 811.

P-ISSN: 1978-2136 | E-ISSN: 2527-676X | Sistem Pemilihan Laptop ...

Techno Nusa Mandiri : Journal of Computing and Information Technology

Sebagai Jurnal Terakreditasi Peringkat 4 berdasarkan

Surat Keputusan Dirjen Risbang SK Nomor 21/E/KPT/2018 